AD WATCH

\title{
"The contemporary, irreverent brand of youth with an independent streak'": BAT's youth promotions in Myanmar
}

S Chapman

Tobacco Control 2004;13:93-94. doi: 10.1136/tc.2003.006585

"British American Tobacco strongly believes children should not smoke, and smoking should only be for adults who understand the risks associated with it. Our Group companies support and run programmes worldwide tackling underage smoking, and we are committed to pooling our resources and experience globally with others in the tobacco industry-and with governments and NGOs - to help prevent youth smoking. Along with the other two largest international tobacco groups-Philip Morris International and Japan Tobacco International - our Group companies have funded and supported more than 130 Youth Smoking Prevention (YSP) programmes in more than 70 countries. ... We fully support laws and regulations on a minimum age for buying tobacco products, and penalties for retailers who break the law. Our company policy worldwide is not to market to anyone under 18 years old, or more if the law in a particular country sets the age higher."-BAT website November 2003

Correspondence to: Professor Simon Chapman, School of Public Health, University of Sydney, Building A27, Sydney, NSW 2006, Australia; simonchapman@ health.usyd.edu.au
$\mathrm{R}$ eaders of the journal will be painfully aware of British American Tobacco's (BAT's) global campaign to convince the world how much it really dislikes youth smoking. But let's cut to Myanmar (formerly Burma) in South East Asia for a short reality check. Thanks to a remorseful former BAT executive from Myanmar who graciously provided me with numerous Powerpoint slide presentations from 1996-1998, we can compare their global PR blather to their business-as-usual practice when no one's checking.

First a few demographics. A March 1998 Bates advertising agency's presentation to BAT got right down to it: $32.5 \%$ of Myanmar's residents are "above 12 [sic] years", and 53\% of the population is families where monthly household income is less than $\$ 30$. With such poverty, promoting single stick sales was the way to go. BAT had promotional teams "identify 555 stick smokers at teashops. No branded vehicles. All under-cover. Smoker rewarded with carton of 555 and 75 ml Johnnie Walker Black Label."

555, Lucky Strike, and Benson \& Hedges are BAT's flagships in Myanmar. An August 1996 Bates Advertising "Get Lucky" presentation on Lucky Strike sought to "Establish brand as the contemporary, irreverent brand of youth with an independent streak." The campaign would feature "American Original Movie Series" including such perennial youth favourites as Top Gun, and the Indiana Jones and Terminator series. A "lifestyle magazine aimed at YAUS" (young adult urban smokers or "youth" when they inadvertently forgot the company code word) with a national circulation of 500000 was to be distributed by teams of "promoter girls" in tea shops and outside cinemas. The Get Lucky magazine would have an "American youth culture theme" which would provide "the perfect vehicle to associate Lucky Strike with youth culture/communicate the Get Lucky brand world". It would also "Build loyalty - potential for database marketing/subscription scheme". A lucky draw would win various prizes including a trip to Hollywood and cash.

\section{"TOWN STORMING"}

Promotion of the magazine would involve "town storming" featuring a "special team of 4 blonde/ American promoter girls" who would "arrive on back of Harley Davidson style bikes (branded)". All Lucky Strike smokers would "have chance to have Polaroid taken with blonde/bike" with all other smokers. Other youth oriented promotions included Benson \& Hedges sponsoring a Top 20 music charts promotion.

Several of the slide sets describe BAT's "Cosmos" promotion in Yangon's (formerly Rangoon) Club Pioneer which was refitted "on the basis that the re-fit reflects elements of the 555 Brand World". The Cosmos events set out "To emphasize that 555 is youthful and modern". A budget of US $\$ 398000$ was allocated for the promotions, including techno music CD door gifts totalling $\$ 21000$. The Cosmos events in the club were supported by "the most advanced, sound, lights and laser system in Myanmar" with equipment valued at $\$ 290000$ being flown in, installed, and operated. TV and other advertising saturated Yangon.

In a classic case study in aspirational marketing, the Cosmos events were pitched at Yangon's upwardly mobile cashed-up class. Entrance to the event was 2700 kyat (\$7.70 at 1998 exchange rate), nearly a week's family income to the poorest half of the Myanmar population.

\section{"DR SPOCK GLUE-ON EARS"}

An event running sheet hints at the indescribable fun. "Opens night with robots escorting dancers to the dance podiums followed by freestyle dancing and ending with confetti gun shots." Bates recognised the "Need [for] fun young imaginative ways to complement the target audiences activities". So the first 200 to arrive were given "Genuine Dr Spock glue-on ears to 
enhance the fun". All attending were given a complimentary "555 Iced Smoothy-blue ice alcoholic cocktail".

The evenings' proceedings were heavily scripted. For example:

- lst Spot: DJ asks “do you want something cool from 555? I can't hear you? Are you sure? Then shout $555 \ldots$ OK" Then gives them a cool break.
- 2nd Spot: DJ repeats above format. Ad libs. Maybe teases. Asks them and when they say "yes" or call "555", he says "no way" and pumps up the music.

BAT, we await your predictable comments via our rapid response facility.

The Powerpoints may be viewed at http://tobacco.health. usyd.edu.au/share/BATBurma/ 